\title{
Flexible conductivity, temperature, and depth sensor for marine environment monitoring*
}

\author{
Altynay Kaidarova ${ }^{1}$, Marco Marengo ${ }^{1}$, Nathan R. Geraldi ${ }^{2}$, Corlos M. Duarte ${ }^{2}$ and Jurgen Kosel ${ }^{1}$ \\ ${ }^{1}$ Computer, Electrical and Mathematical Sciences \& Engineering (CEMSE), King Abdullah University of Science and \\ Technology(KAUST), Thuwal, Kingdom of Saudi Arabia \\ ${ }^{2}$ Red Sea Research Center (RSRC), King Abdullah University of Science and Technology (KAUST) \\ Kingdom of Saudi Arabia, Thuwal 23955 \\ jurgen.kosel@kaust.edu.
}

\begin{abstract}
This paper presents lightweight and flexible sensors for conductivity, temperature, and depth (CTD). CTD sensors are heavily used in oceanography to determine the salinity, which is a critical factor in the determination of density, currents, weather and more.. The graphene sensors are fabricated by laser printing on flexible polyimide. They combine corrosion resistance with good conductivity and piezoresistivity in a robust platform, enabling the detection of conductance, temperature, and pressure. The performance of the graphene sensor was demonstrated in harsh environments with pressures up to $12 \mathrm{MPa}$ and prolonged exposure to highly saline seawater. The printed sensors are minimally intrusive and can therefore be mounted on a wide range of marine animals.
\end{abstract}

Keywords-graphene; conductivity; temperature; pressure; flexible, printable (key words)

\section{INTRODUCTION}

Monitoring of fish migration and behavior in their natural environment is crucial to estimate and preserve the population of various species[1-3] An effective way to obtain such information is by mounting autonomous tags on fish to measure different parameters of their surroundings[3,4]. Miniaturized, low-powered conductivity, temperature and depth (CTD) sensors are becoming strategic devices used for autonomous tags and primary research tools for salinity measurements $[5,6]$. Currently available CTD devices are bulky, rigid and expensive (>\$1000), posing limitations to their broad employment by marine scientists.

Graphene as a material has been extensively exploited recently, due to its superior properties such as high conductivity, flexibility and biocompatibility [7-9]. In this work, we use Laser-Induced Graphene (LIG) for facile production of scalable and flexible CTD sensors, whose electrodes are made without underlying electrode material or additive composites. We integrate three different LIG sensors on one patch, leading to lightweight, durable, multifunctional and printed sensors suitable for marine animal monitoring. The sensitivity and dynamic range of LIG CTD sensors can be tailored via the substrate and one-step laser printing design. The sensors can withstand the harsh environment and extreme pressures of marine environments over extended time periods.

\section{METHODOLODY}

\section{A. Fabircation and Characterisation}

The sensors were directly patterned on a $125 \mu \mathrm{m}$ thick PI film (DuPont, Kapton \# IM301449), while porous conductive carbon networks with a high content of graphene sheets $(40 \pm 5 \mu \mathrm{m})$ were obtained by thermolysis using $\mathrm{CO}_{2}$ laser (Epilog Fusion M2 $10.6 \mu \mathrm{m}$, laser peak power $75 \mathrm{~W}$ ), as shown in Fig. 1. The main parameters of the laser beam $(5 \mathrm{~W}$ power, $10 \mathrm{~cm} / \mathrm{s}$ speed, 1000 pulses per inch (PPI) and $3 \mathrm{~mm}$ working distance) were optimized for good adhesion of the carbon structure to the film. The laser irradiation of PI film leads to breakage of $\mathrm{C}-\mathrm{O}, \mathrm{N}-\mathrm{C}$, and $\mathrm{C}=\mathrm{O}$ bonds and rearrangement of the carbon atoms, leading to the porous graphene, shown in Fig. 2a. The Raman spectrum (Fig. 2b) of LIG reveals three main peaks $\mathrm{D}, \mathrm{G}$ and $2 \mathrm{D}$ at 1360,1580 and $2720 \mathrm{~cm}^{-1}$, respectively, that are in accordance with literature reports $[10,11]$ and indicate the presence of multiple layers of graphene sheets in the porous structure.

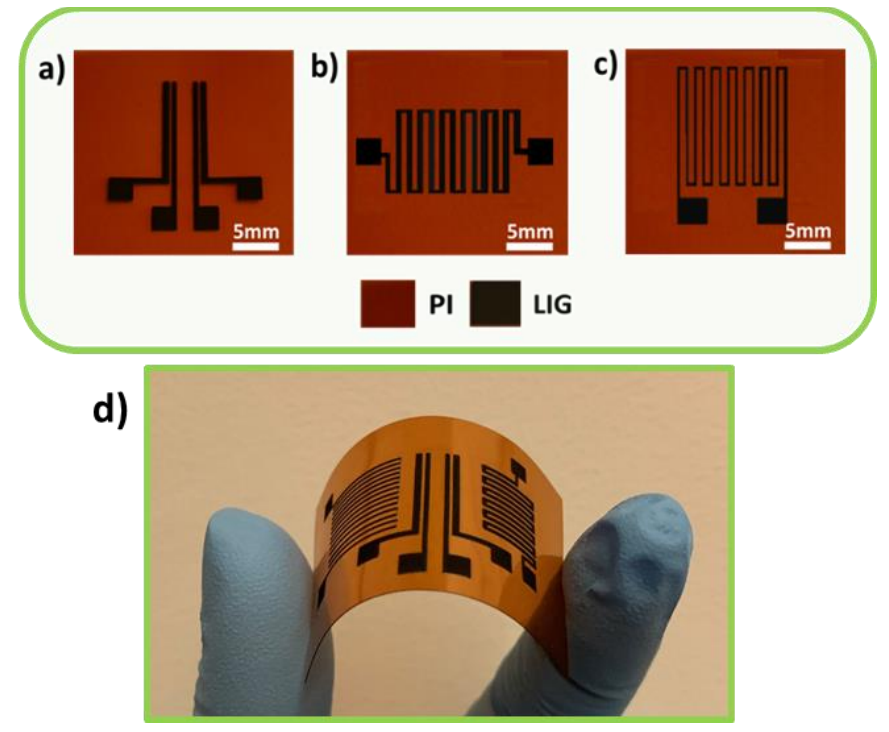

Fig. 1. a) Conductivity cell b) thermistor and c) pressure sensors for flexible and miniaturized CTD board. d) All three sensors combined on one patch. 
For measurements of the salinity of the seawater, three LIG sensors have been employed: conductivity cell, thermistor and pressure sensor. The fabrication process was the same for all reported sensors, except that the LIG electrodes of thermistor and pressure sensors were protected from the interaction with ions (shunt circuits) and biofouling via a PDMS coating of 10 $\mu \mathrm{m}$ thickness (Dow Corning Corp., Slygard $® 184$ ). To provide a stable electrical connection to the sensor, through holes of 120 $\mu \mathrm{m}$ in diameter were created using $30 \mathrm{~W}$ of laser power and 20 $\mathrm{cm} / \mathrm{s}$ speed, and wires were thread through the holes.
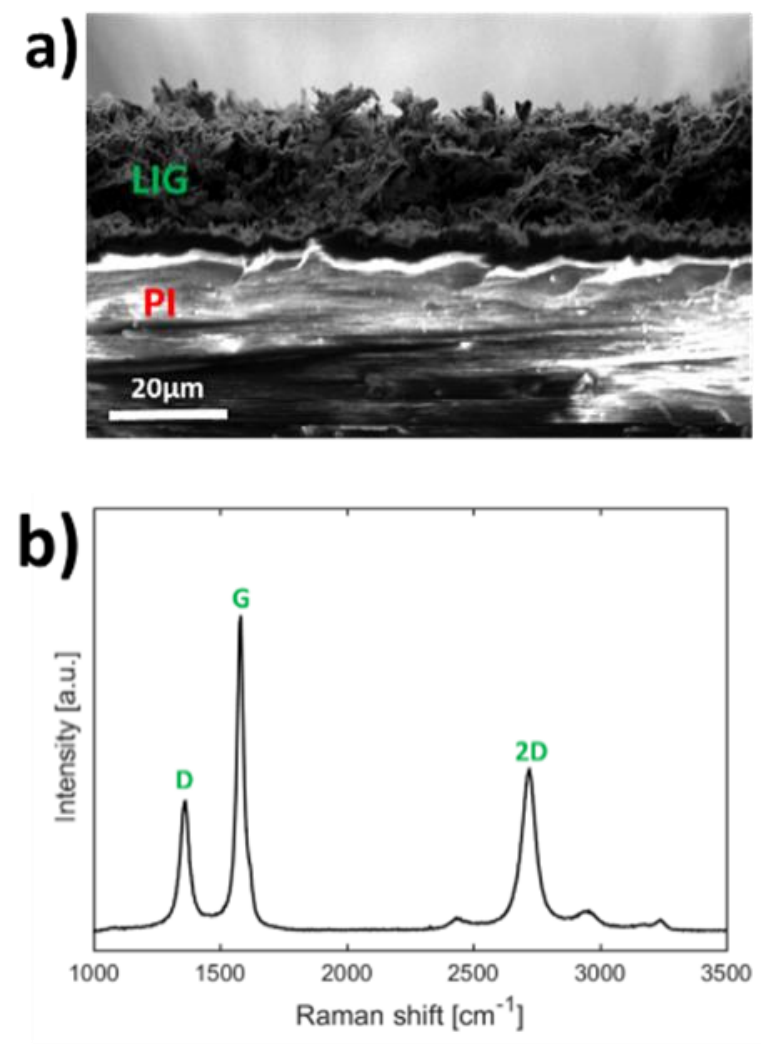

Fig.2 a) Cross-section SEM image of the porous carbon network on top of polyimide. b) Raman spectrum of LIG obtained with $473 \mathrm{~nm}$ laser wavelength.

\section{B. Design}

The design of the CTD platform was driven by several objectives: small size, ease of interfacing to circuit electronics, rapid development and prototyping and low manufacturing cost. A conductivity cell is implemented with four-electrodes, where the outer electrodes supply an AC current and the inner electrodes measure the voltage drop across the medium ( Fig 1a). Such configuration minimizes capacitive parasitic components, due to the electrical double layer (EDL) and reduces the effect of lead resistance and inductance errors between the cell and the meter $[12,13]$. The temperature and pressure sensitive components were structured in a meander shape to provide a large change in resistance, while keeping the minimum electrode width $(\sim 150 \mu \mathrm{m}$, corresponding to the laser spot diameter), as shown in Fig $1 \mathrm{~b}$ and $\mathrm{c}$.

\section{RESUlTS}

The LIG sensors were integrated on the same patch (Fig.1d) and tested individually to establish their feasibility for multi-sensor autonomous CTD device.

\section{A. Conductivity cell performance}

An impedance analyzer (Agilent 4294A) with a four alligators fixture (Keysight 16089D Kelvin/Alligator Clip Leads) was used to record the response of the sensor by immersing it into 10, 18, 26, 34, 42 and 50 psu solutions. As shown in Fig.3, the sensor has a linear response to salinity with the sensitivity of $0.85 \mathrm{mS} / \mathrm{psu}$, and operate over a wide range of frequencies (10 $\mathrm{kHz}-100 \mathrm{kHz}$ ). These characteristics significantly relax the requirements for the circuit of the data storage tags. Temperature affects salinity measurements, due to the increase of mobility of the ions with temperature. Using UNESCO technical guidelines [14], the experimental data points were found to be in very good agreement with the theoretical ones with an accuracy of $0.5 \mathrm{psu}$ (Fig.4a). A test of the response time, carried out with the LIG sensor and a 34 psu solution, confirms that the procedure followed was sufficiently long to guarantee a stable value. To this end, the sensor is immersed in the solution and the conductance is recorded every ten seconds for 5 minutes. A stable value is achieved after 2 minutes, as shown in Fig. 4b.

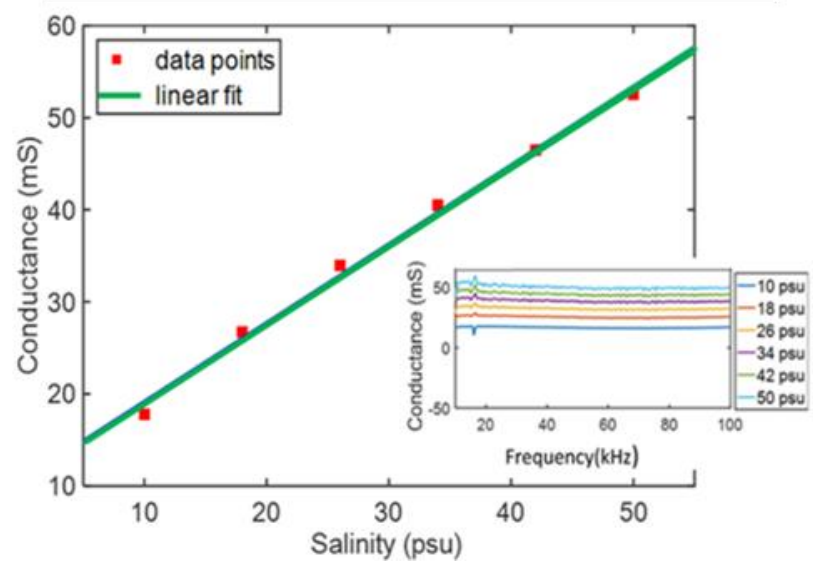

Fig.3 a) The conductance as a function of salinity and the frequency.

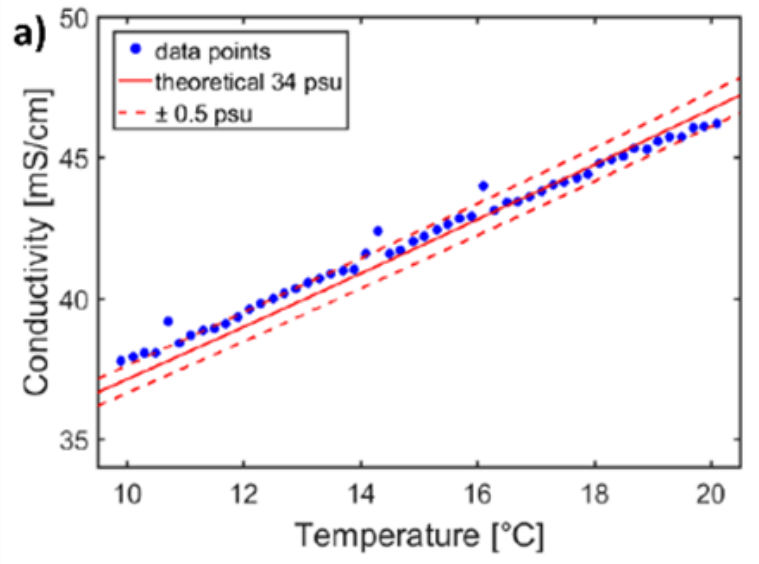




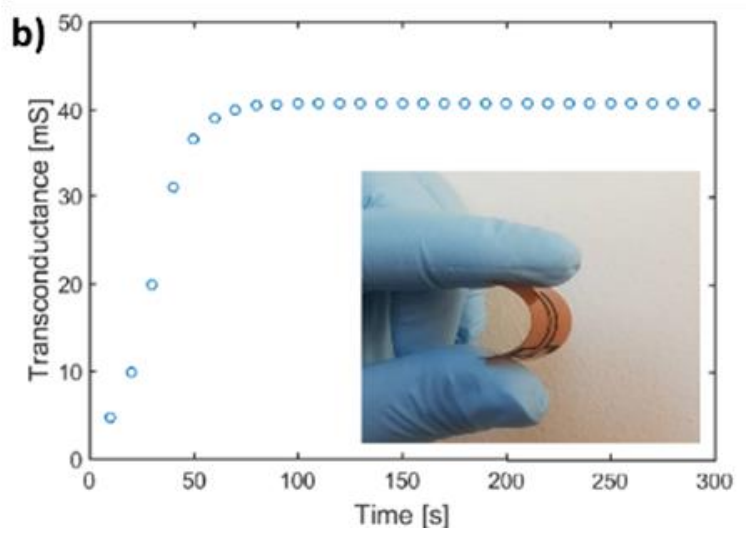

Fig.4 a) Theoretical and experimental results of conductivity as a function of temperature in 34 psu solution. b) Response time of conductivity cell in 34 psu solution. The inset shows the mechanical flexibility of the sensor.

\section{B. Thermistor measurements}

The response of the LIG temperature sensor to a thermal stimulus was examined by immersing the sensor into seawater and increasing the water temperature via a heater (RCT basic, IKA) by $1^{\circ} \mathrm{C}$ every minute and using a thermocouple as reference. A continuous current of $1 \mathrm{~mA}$ was applied through the graphene thermistor (as in all consecutive experiments) to measure the change of electrical resistance. The LIG thermistor had a negative temperature coefficient (NTC) of $-0.57 * 10^{-3} /$ ${ }^{\circ} \mathrm{C}$, which corresponds to the coefficient value of graphite [15]. There is $\cong 1.25 \%$ decrease in resistance, when the temperature was raised from $18^{\circ} \mathrm{C}$ to $40^{\circ} \mathrm{C}$ (Fig.5)

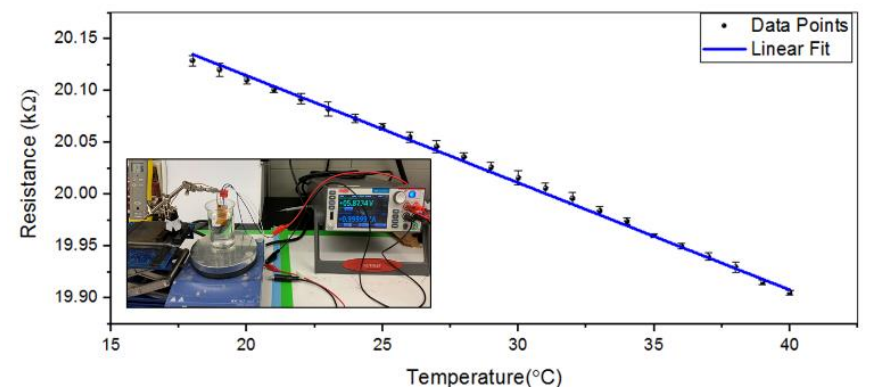

Fig.5 Resistance of LIG thermistor as a function of temperature.

\section{Pressure sensor characteristics}

The LIG pressure sensor was characterized using a compression chamber, which can simulate and control the pressure related up to a depth of $2 \mathrm{~km}$ (DM-TQ-150-1AL/C, Ametek) (Fig. 6a). A metallic cylindrical chamber (3755 PSI, OSECO) was filled with water from the Red Sea and the sensor was placed inside the chamber, where it was connected with waterproof wires for connecting a Keithley source meter. The pressure response of the sensor was induced by the deformation of the graphene conductive network structure, leading to a variation in resistance. The relative change in resistance has a positive trend with increasing pressure with sensitivities of $2 * 10^{-5} \mathrm{kPa}^{-1}$ from $0 \mathrm{~Pa}$ to $\sim 6 \mathrm{MPa}$ and $0.2 * 10^{-5} \mathrm{kPa}^{-1}$ from $\sim 6$ to $\sim 12 \mathrm{MPa}$, which corresponds to $1.2 \mathrm{~km}$ depth in seawater (Fig.6b).
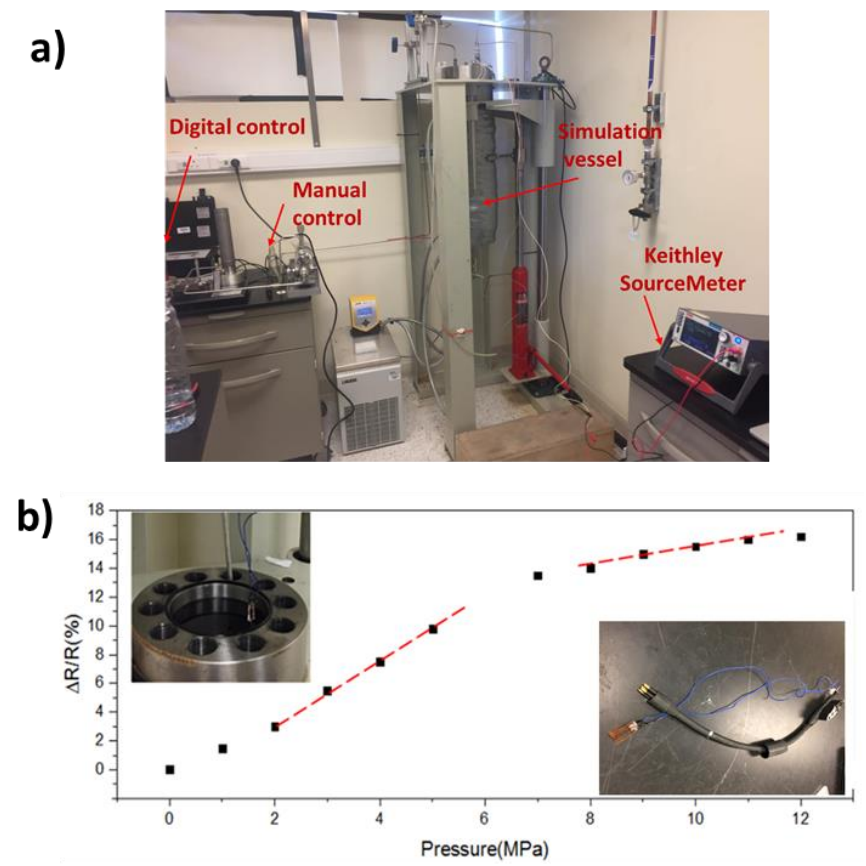

Fig.6 a) Experimental setup for the high-pressure simulation and realtime testing in the harsh seawater environment . b) Resistance response to pressure. The inset shows the limit of detection.

\section{CONCLUSION}

CTD sensors are presented in this paper, consisting of printed LIG on polyimide, which are mechanically flexible, low cost, lightweight and can operate under harsh environmental conditions. The single- step fabrication method by direct laser scribing is a key feature, which paves the way to prototyping and mass fabrication. The process also allows tuning the geometry of the sensors to achieve various sensitivities, dynamic ranges or sizes and provides a platform for the development of miniaturized, flexible and wearable CTD tags. The LIG conductivity cell offers a linear response to salinity, with a sensitivity of $0.85 \mathrm{mS} / \mathrm{psu}$ and an accuracy of $\pm 0.5 \mathrm{psu}$ over a wide range of frequencies $(10-100 \mathrm{kHz})$. A linear relation is also found for the PDMS coated LIG thermistor with a negative temperature coefficient of $0.57^{*} 10^{-3} /{ }^{\circ} \mathrm{C}$. The coated pressure sensor can be deployed down to $1.2 \mathrm{~km}$ depth in the seawater, where the pressure reaches an extreme value of $\sim 12$ $\mathrm{MPa}$, while maintaining a sensitivity of $2 * 10^{-5} \mathrm{kPA}^{-1}$.

\section{ACKNOWLEDGMENT}

This research is a contribution to the CAASE project funded by King Abdullah University of Science and Technology (KAUST) under the KAUST Sensor Initiative. We thank the staff and leadership of the Oceanografic in Valencia for their help and support during the sensor tests. 


\section{REFERENCES}

[1] Thorstad, E.B., Rikardsen, A.H., Alp, A. and Økland, F., 2013. The use of electronic tags in fish research-an overview of fish telemetry methods. Turkish Journal of Fisheries and Aquatic Sciences, 13(5), pp.881-896.

[2] Boehme, L., Lovell, P., Biuw, M., Roquet, F., Nicholson, J., Thorpe, S.E., Meredith, M.P. and Fedak, M., 2009. Animal-borne CTD-Satellite Relay Data Loggers for real-time oceanographic data collection. Ocean Science.

[3] Hooker, S.K. and Boyd, I.L., 2003. Salinity sensors on seals: use of marine predators to carry CTD data loggers. Deep Sea Research Part I: Oceanographic Research Papers, 50(7), pp.927-939.

[4] Boehlert, G.W., Costa, D.P., Crocker, D.E., Green, P., O'Brien, T., Levitus, S. and Le Boeuf, B.J., 2001. Autonomous pinniped environmental samplers: using instrumented animals as oceanographic data collectors. Journal of atmospheric and oceanic technology, 18(11), pp.1882-1893. K. Elissa, "Title of paper if known," unpublished.

[5] Crescentini, M., Bennati, M. and Tartagni, M., 2012. Design of integrated and autonomous conductivity-temperature-depth (CTD) sensors. AEUInternational Journal of Electronics and Communications, 66(8), pp.630635. Y. Yorozu, M.

[6] Mensah, V., Roquet, F., Siegelman-Charbit, L., Picard, B., Pauthenet, E. and Guinet, C., 2018. A correction for the thermal mass-induced errors of CTD tags mounted on marine mammals. Journal of atmospheric and oceanic technology, 35(6), pp.1237-1252.

[7] M.A. Khan, I.R. Hristovski, G. Marinaro and J. Kosel, "Magnetic composite Hydrodynamic Pump with Laser Induced Graphene Electrodes," IEEE Transactions on Magnetics, 53, 11, pp. 1-4, (2017) DOI: 10.1109/TMAG.2017.2707598
[8] Kaidarova, A., Marengo, M., Marinaro, G., Geraldi, N., Duarte, C.M. and Kosel, J., 2018. Flexible and Biofouling Independent Salinity Sensor. Advanced Materials Interfaces, 5(23), p.1801110.

[9] Marengo, M., Marinaro, G. and Kosel, J., 2017, October. Flexible temperature and flow sensor from laser-induced graphene. In 2017 IEEE SENSORS (pp. 1-3). IEEE.

[10] Ferrari, Andrea C., et al. "Raman spectrum of graphene and graphene layers." Physical review letters 97.18 (2006): 187401.]

[11] Cançado, L. Gustavo, et al. "Quantifying defects in graphene via Raman spectroscopy at different excitation energies." Nano letters 11.8 (2011): 3190-3196

[12] Hyldgard, A., et al. "FISH \& CHIPS: four electrode conductivity/salinity sensor on a silicon multi-sensor chip for fisheries research." SENSORS, 2005 IEEE. IEEE, 2005.

[13] Li, Xiujun, and Gerard CM Meijer. "A low-cost and accurate interface for four-electrode conductivity sensors." IEEE Transactions on instrumentation and measurement 54.6 (2005): 2433-2437.

[14] McDougall, Trevor J., et al. "Accurate and computationally efficient algorithms for potential temperature and density of seawater." Journal of Atmospheric and Oceanic Technology20.5 (2003): 730-741.

[15] Tsang, D. K. L., et al. "Graphite thermal expansion relationship for different temperature ranges." Carbon 43.14 (2005): 2902-2906.

[16] Rasul, Najeeb MA, and Ian CF Stewart, eds. The Red Sea: the formation, morphology, oceanography and environment of a young ocean basin. Springer, 2015.

[17] Singh, Swatantra P., et al. "Laser-induced graphene layers and electrodes prevents microbial fouling and exerts antimicrobial action." ACS applied materials \& interfaces 9.21 (2017): 18238-18247. 